\author{
JILL ADLER, DEBORAH BALL, KONRAD KRAINER, FOU-LAI LIN \\ and JARMILA NOVOTNA
}

\title{
REFLECTIONS ON AN EMERGING FIELD: RESEARCHING MATHEMATICS TEACHER EDUCATION*
}

\begin{abstract}
This paper reports a survey of research in mathematics teacher education from 1999 to 2003 done by an international team of five mathematics educators and researchers. The survey included published research in international mathematics education journals, international handbooks of mathematics education and international mathematics education conference proceedings. Some regional sources from various parts of the world were also included. We investigated who was writing, from and in what settings, with what theoretical frameworks, and with what sorts of study designs for what core questions. We also examined the range of findings and conclusions produced in these studies. Our analysis presented here focuses on four themes that stood out from our initial investigation of almost 300 published papers, and systematically elaborated through a focused study of a 160 papers across key journals and conference proceedings in the field. From this vantage point, the paper offers a reflection on the current state of the field of mathematics teacher education research. Our aim is to stimulate discussion that can support the development of the field, not make final pronouncements about its nature.
\end{abstract}

KEY WORDS: survey of field, teacher education research, teaching

\section{INTRODUCTION}

This paper reports an international survey of published research in mathematics teacher education in the years 1999-2003, conducted at the invitation of the ICME10 (2004) program committee. $\mathrm{We}^{1}$ begin with a discussion of the current field of mathematics teacher education, the emergence of related research, and the value of critical reflection on progress at this juncture. We then discuss why we focused on research, and the methods we adopted - where and how we looked in order to construct the survey we did. This process brought to the fore a number of themes, in particular, the

\footnotetext{
*The research presented in this paper was done by five mathematics education researchers, the authors listed above, and presented at ICME10 in Copenhagen in July 2004. This Survey Team (Survey Team 3) was nominated by the International Program Committee for the Congress and asked to survey "Professional Development of Mathematics Teachers" and present this in a plenary at the Congress. A copy of the presentation can be viewed at: http://www.wits.ac.za/jadler/presentations.html. An earlier version of this paper will also appear in the ICME10 proceedings.
} 
research methods in use, issues of authorship and voice, and consequences for the substance of research being done. We observed a field currently dominated by small scale studies in English-speaking countries. The studies we surveyed focused on teachers' learning in the context of a reform agenda, and researchers, typically, were studying aspects of reform programs offered by or in their own institutions. We present these as claims, each of which is followed by a range of commentaries. This format of ranging commentaries is unusual, yet in our view, powerful. It is a function of the diversity in the research team. It was possible for us all to agree on the observed themes, and to construct claims on the basis of the survey. However, our perspectives on what these observations and claims mean for, and about, our field differ. We thus do not present sharply honed singular arguments; but rather a range of interpretations which we hope will stimulate further debate. We conclude the paper in the same way, offering a range of suggestions for the field of mathematics teacher education research.

\section{MAthematics TEACHER EDUCATION IN 2004}

We are currently witnessing what can be called the "massification" of mathematics as a school subject. In many countries today there is an extensive move to make mathematics accessible for all. Mathematics is viewed as a necessary competency for critical citizenship. An obvious consequence of the increasing demand for mathematics proficiency ${ }^{2}$ for all is an increase in the need for quality teaching. ${ }^{3}$ That this need is evident at all levels of schooling is unprecedented. Although the demand for quality teaching is high at the secondary and tertiary levels of schooling, where mathematics is a specialization subject, quality teaching is even more important at levels where mathematics is a general requirement. More teachers and better mathematics teaching are needed if mathematical proficiency is indeed to become a widely held competence. Of course, quality instruction depends on teachers, and so their preparation and continuing professional development is crucial.

However, with different class sizes and material resource bases in different countries, it is not obvious what it might mean to enable quality teaching in different contexts. ${ }^{4}$ In some countries (e.g., South Africa), many mathematics teachers are teaching in large (over 40 learners) classrooms often severely lacking even basic resources. Class size also varies within countries (e.g., in the US, there is a relatively high pupil-teacher ratio in urban schools while more affluent suburban schools may often enjoy lower class sizes). In many contexts, mathematics classrooms also include a greater range of learners who live in and bring with them diverse cultural practices 
and languages, as well as linguistic and mathematical competences. This diversity adds to the challenge of providing quality teaching. Globalization is increasing the dominance of English as a language of instruction around the world. More and more learners have to learn mathematics in English, a language that is not their main spoken language. This phenomenon is no longer specific to (British) post colonial countries. There are similar pressures for English language competence in Scandinavian ${ }^{5}$ as well as some European countries (e.g., the Czech Republic). This quick look at a few different classrooms brings to life a significant part of preparing mathematics teachers for quality instruction, that is, preparing teachers to engage and mediate the increasing diversity of their learners.

But what is it that mathematics teachers need to know, and know how to do, to enact quality instruction across these diverse conditions? How is teacher education research and practice dealing with these current challenges?

Diversity across those learning to teach is also increasing. Teacherlearners study in varying group sizes (some as large as 80), and in groups which are culturally homogenous as well as culturally diverse. They prepare for their profession in diverse socio-economic conditions, with differences in the materials and resources being used across teacher education settings. A significant additional note about who is (re)learning to teach mathematics, is that differences are increasing between teacher educators and their 'learners'-i.e., prospective and practicing teachers. Teacher-learners bring increasingly diverse mathematical histories. In many countries prospective elementary teachers have learned limited mathematics in school. In countries where there are great shortages, even prospective secondary teachers are entering training with relatively poor mathematical experiences and performance at school. This reveals that we are dealing with different kinds and levels of under-preparedness, a phenomenon that extends into in-service teacher education. Many practicing teachers, for different reasons, have not learned some of the content they are now required to teach, or they have not learned it in ways that enable them to teach what is now required. In particular, curriculum reform processes in mathematics across different countries resulted in many teachers now having to teach a curriculum that is quite different from the one for which they were educated, and from one with which they had become experienced - and often also successful.

Teachers need support if the goal of mathematical proficiency for all is to be reached. The demands this makes on teacher educators and the enterprise of teacher education are substantial, and often under-appreciated. These, in turn, shape the context in which research on mathematics education is developing. 


\section{THE TIMELINESS OF A SURVEY OF RESEARCH ON MATHEMATICS TEACHER EDUCATION}

The timeliness of the survey reported in this paper is not only a function of the current demands on mathematics teaching and teacher education. While still relatively young, mathematics teacher education (MTE) has mushroomed in the past five years in particular with multiple approaches and initiatives evident. For example, there were over 60 contributions on mathematics teacher education across various parts of the ICME10 program (relevant Topic Study Groups, Discussion Groups and the Thematic Afternoon) from a wide range of countries and regions as listed on the congress website. ${ }^{6}$ It is also interesting to note that only ten years ago there was very little research on processes of mathematics teacher education, in contrast to research on teachers' beliefs, knowledge, practice, biographies, expert-novice comparisons. Now, we have with the Journal of Mathematics Teacher Education, an international journal dedicated to researching teacher education; focus strands in major conferences, particularly PME; as well as increased attention to mathematics teacher education in recently published international handbooks in the field. ${ }^{7}$ The importance of teacher education for our community is further signaled by the invitation to develop and present this survey at ICME10, and in the plans for the fifteenth ICMI Study, currently underway, whose single focus is the professional education of teachers of mathematics around the world.

The Survey Team saw as its responsibility to describe "where are we," globally, in the field and within ICME, and so complement the work of ICMI Study 15 . We intended to both survey and report and also contribute to the growth of this relatively new, but critically important, research field. Survey Team 1 (reporting on research and practice in mathematics education) ${ }^{8}$ noted the shifts over time in the field of mathematics education research, starting with studies focused on curriculum, then shifting to a focus on learners, then teachers.

There are a number of publications presenting focused surveys or perspectives on the field between 1999 and 2004, for example Krainer et al. (1999); Lin and Cooney (2001); Peter-Koop et al. (2003), Strässer et al. (2004). Most of these emerged from conferences focused on mathematics teacher education, and they have been supplemented by survey papers, offering overview perspectives on the growth of research in mathematics teacher education, for example Lerman (2001); Llinares and Krainer (in press). The survey we undertook adds to this growth of knowledge in that we attempted a broad brush of the field focused on the years 1999-2003. 


\section{Central Questions}

For the Survey team and its work, this meant that a massive amount of material was available to be examined. We decided that, in order to do a useful survey of the field, a clear focus would be helpful. Both because of our own interests, and the demands for research knowledge about teacher development, we posed the following question:

What is research in the field contributing to the improvement of the education of teachers of mathematics?

More specifically, given that the task of mathematics teacher education is to work with large groups of teachers, in diverse contexts, so that they are able to teach mathematics well in diverse settings and conditions, then

- what stands out about research that focuses on mathematics teacher education over the examined period?

- what research is being produced that can contribute to the massive need for supporting teachers' learning and development? We were interested in inquiries of two basic types:

- Understanding how teachers learn, and from what opportunities, and under what conditions

- Improving teachers' opportunities to learn

\section{DELINEATION OF MATHEMATICS TEACHER EDUCATION RESEARCH}

Mathematics teacher education is a very broad field, and so a key task, as with any survey, was to agree on the meaning of central notions. First, we agreed that by "teachers," we would include student teachers, classroom teachers, and teacher educators. For us that also - importantly - entailed delineating and agreeing on what we would count as teacher education research. The Journal of Mathematics Teacher Education (JMTE) initiated in 1998 became a useful marker for us, as the research reported there was clearly mathematics teacher education research. We needed, for example, to be able to identify those papers in PME proceedings, or in journals not dedicated to teacher education, e.g., the Journal for Research in Mathematics Education (JRME), that would "count" in our survey. There is much work to do to define the broad field we encountered, and this will be developed in a more detailed paper on the first claims to be discussed below.

Our perusal of JMTE revealed many studies that occurred in the context of teacher education, and focused on teachers' learning and change over time. In addition to research on teachers' learning, there were numerous 
papers on teachers' beliefs, knowledge and practices. Some of these were not focused on teachers' learning or changes in their beliefs, knowledge and practices, and some were not situated in the context of teacher education. In the survey presented here, we included studies on teachers' knowledge, beliefs and practices where the teachers being studied were participating in teacher education programs, but not studies that investigated teachers' knowledge, beliefs and practices independently of questions of learning or change. The boundary, therefore, around what does and does not count as teacher education research in relation to areas like teachers' knowledge, beliefs and practices is somewhat blurred, and its delineation will require further work.

In addition to the papers already mentioned, we included a third set of papers in our survey: theoretical papers focused on mathematics teacher education and papers that provided some meta-analysis of the field.

We move on now to describe and explain what we did and what we found. We need to add that we are all deeply invested in the enterprise of teacher education. We are all educators, and researchers in mathematics education research, and mathematics teacher education practitioners, yet with diverse experiences and from diverse contexts. Our different experiences shaped our work, our interpretations, and the nature of our analyses, and constituted a resource for the quality of our work. Our different orientations to research in the field, became a tool for broadening the scope of what is 'seen'. At the same time, our different perspectives presented us with challenges. Unlike other collective research endeavors where researchers come to work together over time, and usually in near locations, we were distanced, geographically, culturally, and in the work we do. In addition, as an invited team, this survey work needed to be done alongside each of our own research commitments, placing significant constraints on our individual and collective time. As we explain below, we had to limit the scope of our survey (what we looked at) to meet these challenges and constraints.

\section{THE METHODS WE USED}

\subsection{What we looked at (included and excluded)}

All the domains of mathematics teacher education were taken into account: pre-service and in-service, as well as primary and secondary teacher education. By this relatively broad definition of professional development, we hoped to gain insight into issues that are topical in particular contexts, and into the kinds of problems that appear to be common, or substantively different, across levels and contexts. 
We selected from multiple outlets for this work, including peer reviewed journals, international handbooks and key conference proceedings. Initially, we looked across key international journals and conference proceedings, as well as a handful of more regional publications (journals and proceedings) in Asia and Europe, i.e., published in languages other than English where we had direct access to these. Our original intention was to spread our review widely, finding ways to access important research in the field published in the full range of journals and focused conference proceedings, and in a range of languages. However, time and resources mitigated against us. We restricted the survey to key international sources, supported by other less systematically defined texts to which we had direct access, and which we could use, if needed, to confirm or contradict trends as these became visible through the review. We also restricted the survey in relation to time, and focused on published research between 1999 (1998 in the case of JMTE as this is the year it was launched) and 2003, that is, since the previous ICME Congress.

The full range of what we looked at is listed in Table I below (totalling 282 papers). The focus of our report is nevertheless on the highlighted publications that constitute a careful selection of those journals and proceedings widely considered as either leading publications in our field, or central to the work of the survey ${ }^{9}$ (160 papers). We noted with interest the very small number of papers focused on teacher education research in Educational Studies in Mathematics (ESM, see below), a function we believe of the launch of JMTE in 1998. Hence we focused centrally on the content and scope of JMTE.

\subsection{How we looked}

To launch our work, we developed a framework for looking across ranging publications, reproduced in Table II below. This facilitated establishing a shared framework necessary to implement a reliable survey.

A great deal of information is contained in the summaries we produced of the 282 papers read and captured through this framework. A glance across and down the rows and columns of the table reveals that we captured the who (who was writing/doing the research, and from where), the how (what methods were used) and the what (what was being studied, theoretical orientations, assumptions and outcomes).

The value of working this way was that it enabled us to look across and discuss the wide range of papers we had read. It also enabled the job to be done within a reasonable time frame. In addition, this kind of capturing of the data enabled us to examine trends that we might otherwise not have seen. And as with any framework or structure, there were also limitations 
TABLE I

Journals and proceedings included in our survey

Journals (126 papers in all;
72 in focus)
Handbooks

Total

$\begin{array}{ll}\text { Journal of Mathematics Teacher Education } & 65 \\ \text { JMTE, 1998-2003 } & 7 \\ \text { Journal for Research in Mathematics Education } & 7 \\ \text { JRME, 1999-2003 }\end{array}$

Journal of Mathematical Thinking \& Learning JMT\&L, 1999-2003

Journal of Teacher Education JTE, 1999-2003 3

Educational Studies in Mathematics ESM, 2 1999-2002

Mathematics Teacher Education and 34 Development MTED, 1999-2003

Pacific Journal of Teacher Education, 1999-2003, together with the Chinese Journal of Science Education, 1999-2003

Pedagogika, 1999-2002

Proceedings of Psychology of Mathematics 88

Education Conferences 1999-2003

Papers from discussion group on teacher education in proceedings ICME9, 2000 (a selection of these appears as a special issue of MTED in 2001)

Conferences of the European Society for Research in Mathematics Education CERME, 1999-2003

Symposium on Elementary Mathematics Teaching: SEMT 2001 and SEMT 2003, together with the Mediterranean Conferences on Mathematical Education MedConf 2000 and 2003

National Science Council and Teacher Education Conferences Taiwan, 1999-2001

Second International Handbook of Mathematics Education

to the way we went about this work. In particular, when a research team undertakes a survey, they typically do so with a more focused question and theoretical orientation and so are more directed in theoretical underpinnings of survey. This kind of orientation is thus absent in our survey, by design. 


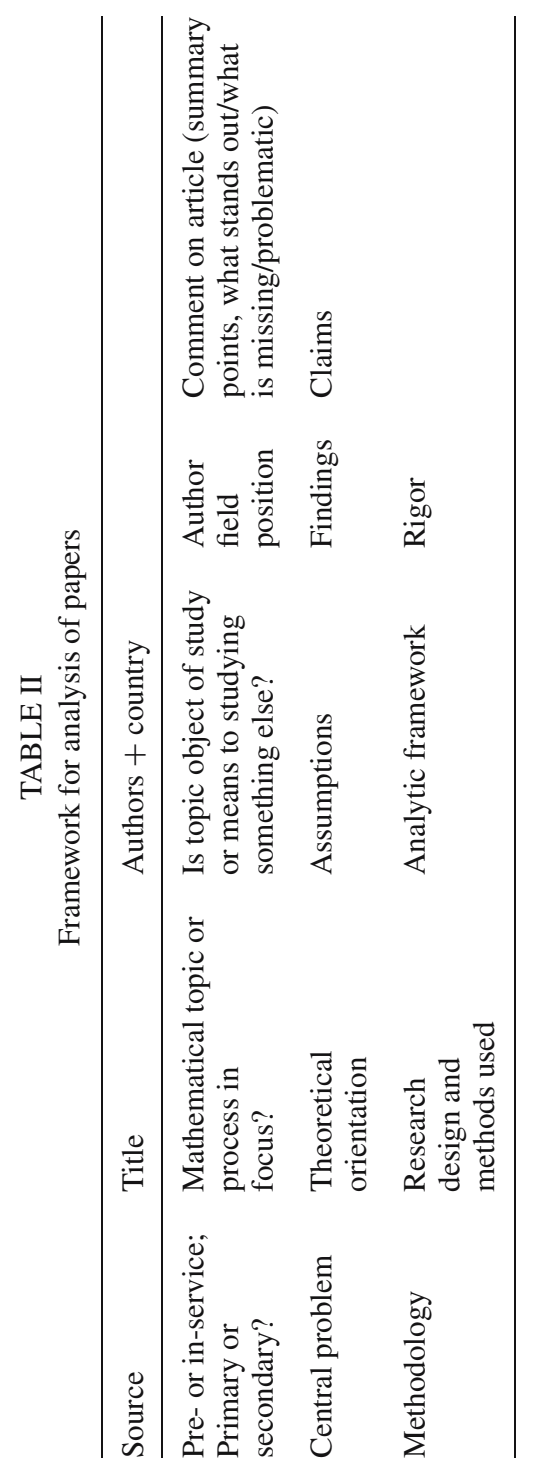


There are interesting things to report about all that we noticed as we read. We focus here, however, on those things that struck us as we began to look across all that we had captured. These fall into the highlighted parts of Table II. We formulated four main claims about these major findings. Our claims focus on: (a) where the research in this domain is being done; (b) how it is being done, (c) by whom, and (d) the consequences of these trends. ${ }^{10}$

The claims presented below are not necessarily surprising. They reflect the progress we see in some areas. At the same time, we discuss some trends that we believe are troubling. Each of the claims presented is followed by three different comments - each a particular interpretation of the claim by one of us (authors). These multiple commentaries reflect our collective, and sometimes differing, views on the implications of what we saw for the field.

\section{EMERGING THEMES}

\subsection{Claim 1: Small-scale qualitative research predominates}

By "small scale qualitative research," we mean studies that focus on a single teacher or on small groups of teachers $(n<20)$ within individual programs or courses. Table III shows a systematic analysis of 160 papers in JMTE, JRME and PME. The first line indicates 21 studies dealing with one teacher or teacher educator's learning. Consider the following example from a Danish researcher, Jeppe Skott (2001), who investigates very carefully how Christopher, a novice teacher, copes with the complexities of his mathematics classroom. Studies involving two to nine teachers were those that focused on, for example, a study of a group of teachers within one school site or program. The third row in the table refers to papers

TABLE III

Numbers of teachers studied in each JMTE, JRME and PME papers

\begin{tabular}{llll}
\hline Numbers of teachers & $\begin{array}{l}\text { JMTE (No. of } \\
\operatorname{articles}(N=65))\end{array}$ & $\begin{array}{l}\text { PME (No. of } \\
\operatorname{articles}(N=88))\end{array}$ & $\begin{array}{l}\text { JRME (No. of } \\
\operatorname{articles}(N=7))\end{array}$ \\
\hline 1 & 10 & 10 & 1 \\
$2-9$ & 18 & 34 & 2 \\
$10-19$ & 10 & 12 & 1 \\
$20-99$ & 14 & 20 & 3 \\
$100-553$ & 5 & 5 & 0 \\
No data or not claiming & 8 & 7 & 0 \\
to be empirical & & & \\
\hline
\end{tabular}


reporting on investigations with, for example, an entire faculty; the fourth - an institute or larger group; and the fifth refers to survey research, and so far larger samples of teachers in the study. The table also indicates what we referred to earlier as meta-analysis studies, those that are theoretical or conceptual with no explicitly stated empirical base. Summing this up, there are 98 (out of 160, more than 60\%) papers where there were fewer than 20 teachers in the study. Taking out those 15 papers that don't include empirical data or don't claim to be empirical, the percentage is even near $70 \%$ (98 out of 145). Hence, we observed that a significant percentage of papers are small case studies.

\subsubsection{Commentary 1 (Konrad)}

The distribution of cases along the five categories including the dominance of small scale research reflects the complexity of the field. For example, study groups at schools and even most entire mathematics faculties at schools have fewer than 20 teachers. A large number of pre-service teacher education classes or summer schools have these numbers of participants.

Only recently, given the results of international comparative studies like TIMSS and PISA, and the growing demands on a better teacher education and more knowledge about its effects, educational policy has begun to realize the importance of research in teacher education. This might give rise to bigger projects where large scale studies are done. In addition, it makes sense that, in a new emerging field, researchers first refer to a small number of cases, and even to studies of one single teacher, in order to better understand these particular cases and to further develop theoretical frameworks, methodologies and instruments. On that basis it is then easier to build on hypotheses that can also be examined with regard to larger studies. From that point of view, it seems natural that the interest in particularization precedes generalization. Also, investigating teachers always means to put into consideration their interests, to share the goal of the research with them and to negotiate their role and part in the study. This is a difference, for example, to research on students where such questions of participation, communication, validation of results are not usually necessary. In addition, research in teacher education is often more complex since it deals not only with the beliefs, knowledge and practices of teachers but also students' beliefs and knowledge, as well as with the interaction between teachers and students, and the interaction between teacher educators and teachers. Thus, having teachers as the focus of research leads to high complexity. This increases the tendency to keep the sample small in order to reduce complexity. Teacher education needs both - the particular, and the general. However, there is also some general in the particular, and there is always the particular hidden in the general. 
Small case studies have an advantage for the theory-practice relationship since it is easier to integrate teachers into research. Also, research results from such studies can be written in the form of "stories" which give an authentic view of practice and give principals, administrators and policy makers an insight into the complexity of change in the teaching profession. Such studies also provide useful contrasts to tables of percentages that can give the impression that teacher education and teachers' growth is as easy as counting numbers and calculating means. In addition, such stories are also a good starting point for working with teachers, in particular because they can compare their situation with those of the case.

Finally, it is also interesting to reflect on the need expressed by policy makers for large scale studies. We need to engage policy makers and show them a single teacher, thus revealing how complex is teachers' learning and so avoid falling into the trap of having some narrow conceptions of "best practice" that they believe can be disseminated.

\subsubsection{Commentary 2 (Fou-Lai)}

Indeed, it is a natural state that particularization comes before generalization for an emerging field. Developing a theory of teacher learning is a key issue for research on mathematics teacher education: conceptualizing, modeling and theorizing are considered as three stages of development. Small-scale qualitative studies make significant contributions for conceptualizing the complexity of teacher education and modeling individual teachers' learning process. Some of the reviewed case studies have developed models of individual teacher's learning. ${ }^{11}$ Studies based on different perspectives naturally produce different results. The results of those in-depth small scale qualitative studies could be used as fundamental data for secondary analyses that seek to contribute to theory across studies. When theorizing, large-scale studies are needed for testing the hypotheses.

\subsubsection{Commentary 3 (Deborah)}

Let me elaborate the last point made by Fou-Lai. Three types of studies are missing. There is a notable absence of large scale studies, and these are needed to understand the larger landscape of teachers' opportunities for learning around the world and within countries and to contribute to theories of learning to teach. For example, we know astonishingly little about the range of ways teachers acquire - or don't - the mathematical knowledge needed for teaching. Small studies don't help us sufficiently to understand at larger scale what these learning opportunities look like. Also notably missing are cross-case analyses. For example, strong beliefs exist about methods that help teachers to develop particular kinds of mathematical 
knowledge for teaching. Without cross case analyses, we lack opportunities to test those beliefs, to treat them as hypotheses and so to learn about how different approaches, programs and settings affect the content knowledge teachers need to learn how to teach. Finally, we also lack longitudinal studies. Many of the studies we looked at were short term. By way of example, teachers' knowledge develops across many years as they participate in professional development activity, use new curriculum materials, and meet new students. Without studies that follow teachers over time, our understanding of how teachers learn and under what conditions is lacking.

\subsection{Claim 2: Most teacher education research is conducted by teacher educators studying the teachers with whom they are working}

Our focused analysis of papers in JMTE and JRME and in PME proceedings between 1999 and 2003 forcefully bears out this claim. Of articles representing research that focus on teacher education, $90 \%$ of JMTE articles, $82 \%$ of PME and $72 \%$ of JRME $^{12}$ articles were of this type.

\subsubsection{Commentary 1 (Jarmila)}

This pattern is due to the very nature of the teacher education profession. One of the main objectives of teacher training is to determine the balance between theoretical and practical knowledge and skills. The basic question concerns the content and extent of knowledge required from future teachers. It is obvious that this question permeates through the observations and analyses in teacher education research.

In addition, mathematics teacher educators' professional responsibilities include both research and teaching. Research is one aspect of teacher educators' professional development. This kind of research is also an important part of teacher educators' learning to improve their practice. Finally, institutions of education differ from other kinds of institutions in that they provide direct access to teacher education practice and to school. There is thus ready accessibility for teacher educators' pursuit of important research interests.

\subsubsection{Commentary 2 (Konrad)}

Research done in the context of teacher education is a special kind of research that intersects practice. Teacher educators have the double role of intervening and investigating, or in other words, of improving and understanding. In addition, both aspects are strongly interrelated. This contributes to the complexity of this field. We do need more external research, 
in particular, large scale studies. However, this will entail more specifically funded projects.

It is also important to engage teachers in research activities, for example by integrating them into research projects led by academic researchers or by supporting them to critically and systematically reflect on their own practice within collaborative action research projects. Teachers tend not to read research papers within the context of their work, but being involved in projects such as those mentioned above, bridges might be built. It is important that teachers learn to balance nearness and distance, and that they gain interest in their particular challenges but also the general problems.

\subsubsection{Commentary 3 (Jill)}

While agreeing with much that has been commented on above, I would like to add to the issue of nearness and distance. When you have an investment in which you are teaching, it can be difficult to take a skeptical stance towards that work. Important questions that need to be asked might be missed. So, one critical question is what we need to do to help ourselves take such a skeptical stance towards that work. One way is to invite "external eyes" to gaze in with us on what we are doing. Another way is to develop strong and effective theoretical languages that enable us to create a distance between us and what we are looking at. We need to do more to develop strong language(s) of description for researching mathematics teacher education.

\subsection{Claim 3: Research in countries where English is the national language dominates the literature}

In JMTE between 1998 and 2003, 80\% of the articles were from such countries. In JRME this figure is $71 \%$. It is less stark, but nevertheless prevalent, in PME between 1999 and 2003, where the percentage is 43\%.

The detail in Table IV helps us to focus in further. Presenting the information across regions at the same time hides some interesting phenomena inside regions. For example, in the Middle East, all of the papers we read were from Israel. Similarly, in Africa, all the papers were from South Africa, and in Asia, all from Taiwan. In North America, the vast majority are from the US, and, indeed, there is a remarkable predominance of US authored papers in JMTE and JRME overall. Of course, dominance is not only a phenomenon across countries and regions. Within regions and individual countries, it manifests again a feature which is not visible from the table, nor from our survey. 
TABLE IV

Where is research being done? Two major examples

\begin{tabular}{llll}
\hline & JMTE $(n=65)$ & PME $(n=88)$ & JRME $(n=7)$ \\
\hline North America & $68 \%(65 \%$ US $)$ & $30 \%(24 \%$ US $)$ & $57 \%$ (all US) \\
Oceania & $8 \%$ & $9 \%$ & 0 \\
Europe & $15 \%(5 \%$ UK) & $25 \%(6 \%$ UK) & $14 \%$ \\
Africa & $3 \%$ (all South Africa) & $8 \%(6 \%$ South Africa) & $14 \%$ (all South Africa) \\
Asia & $5 \%$ & $9 \%(7 \%$ Taiwan) & 0 \\
South and & 0 & $3 \%$ (all Brazil) & 0 \\
$\quad$ Central America & & & \\
Inter-continental & 0 & 0 & 0 \\
Middle East & $2 \%$ (all Israel) & $14 \%$ (all Israel) & $14 \%$ (all Israel) \\
\hline
\end{tabular}

\subsubsection{Commentary 1 (Jill)}

These disparities are not surprising. The prevalence and increasing hegemony of English, however uncomfortable, is widely acknowledged, and was referred to in the opening ceremony of the ICME10 Congress. But from the perspective of a domain of mathematics teacher education research, the disparities are deeply troubling. For some people in our community, their "local" become global. Their particulars become the basis of the general. In others, their local remains local; indeed they do not even get heard. What problems, and whose problems then come to constitute the field? This is a critical question for us, particularly if we reflect back for a moment on the description of diverse learners and teacher-learners across classroom and teacher education contexts earlier in this article.

One example from a study of teacher professional development and curriculum change in six rural elementary schools in South Africa will suffice to highlight this issue. In an in-depth study of teachers' discourses and practices, Marneweck (2005) shows that through their participation in a curriculum change and professional development project, the teachers forged a complex practice with a significant shift in their social relations from isolation to collaboration. In addition, in two of the schools, strong leadership emerged over time. However, despite the emergence of collaborative social relations across schools and leadership in some schools, there was little substantive instructional change across all teachers' practices. In the end, the teachers did not offer qualitatively better learning experiences in their classrooms, though they believed that they did. The newly formed social relations were an insufficient base from which the horizons to the knowledge and practices forged by them through apartheid education and conditions could be challenged and grown. Collaboration as central to teacher learning, and leadership as central to curriculum change 
are common discourses in professional development literature. These are areas where perhaps the local is assumed to be the global.

\subsubsection{Commentary 2 (Fou-Lai)}

Mathematics education, as a field of study, can be traced back 30-40 years, with strong roots in the United States, Europe and Australia. The presentation of Survey Team 1, ICME10, showed the shift of research foci in mathematics education starting from a focus on curricula in the 1970s, then shifting to a focus on learners in the 1980s-1990s, and more recently there has been a shift to a focus on teachers. These developmental shifts seem natural since information resulting from research on curricula and learners very often are necessary as foundation for research on teachers. Those that start first, then can base their accumulated knowledge on curricula and learners to move on studying teachers. Thus, this is rather a natural development. The dominance of research from English speaking countries we witnessed is thus understandable.

However, there are other factors that exacerbate this dominance. Many students from other countries take mathematics education programs in the US, UK, Australia, Canada. When these students return to their homelands, and undertake research, they often base these on the perspectives they have learned from abroad. For example, the following topics are pursued: Changes of beliefs, growth of pedagogical content knowledge, and different degrees of awareness of the complexity of teaching. Studies that are based on the same research perspectives are often merely seen as replication, and thus rejected when submitted for publication. This stands in interesting contrast to the natural sciences where replicated experimental studies have their value. Replication studies in mathematics education are not favored by journal reviewers. Comments from reviewers are that the research is not innovative and so not contributing to the field.

Recently (2003) a new international journal in mathematics and science education ${ }^{13}$ has been launched with a support system for authors whose mother tongue is not English. In this journal, the editorials encourage researchers to take societal and cultural practices into account. Hopefully, the publication of this journal will gradually change the phenomena of dominance of authors with English as first language in the field of mathematics education.

\subsubsection{Commentary 3 (Deborah)}

As a person who comes from one of these English-speaking countries, I share the sense of how disturbing this is - of what we fail to learn and how we become persuaded that what we know from local settings is somehow more general in our field. And what this caused me to reflect on is what this might mean for the induction of new researchers where English is 
the main language. For instance, it is important in the education of new researchers to include the development of a disposition and set of skills to actively seek broader literature from more countries, to hold a more skeptical stance about beliefs and generalizations developed in one's own context or country. It is important to develop a stance that avoids confusion between the local and the global. And so it is important to be able to work (read and speak) in more than one language, something that doctoral programs in many English-speaking countries do not currently require.

Moving on to our fourth claim: The first three claims combine to shape this emerging field in mathematics teacher education and we ask the question: What are the consequences for a field that is characterized in these ways: by a predominance of small scale qualitative studies (how); teacher educators studying their own contexts (who); and a predominance of publications from countries where English is a national language (where). In other words, the how, the who and the where have important consequences for the what we are learning, and that takes us to Claim 4.

\subsection{Claim 4: Some questions have been studied, not exhaustively, but extensively, while other important questions remain unexamined.}

We noted many articles that involve efforts to show that particular programs of teacher education 'work'. Interestingly, you can understand how this particular trend follows from our second claim: that the research is often conducted by people studying their own program. A person designs a program and wants to show that it works. It is not so surprising that research aimed at showing effectiveness of particular approaches predominate. This is how innovative ideas are shared, substantiated, and thus gain currency.

We also found a large number of papers dealing with reform processes, particularly in the US. These include studies of teachers learning or relearning mathematics, teachers learning about students' thinking, their language, their orientations, and pedagogical practices. These are all clearly instances where the local becomes the global. In this case, the centrality of the US mathematics reform efforts has shaped the work of US researchers. And then because those in the US get to publish more, issues of concern in the United States become a dominant theme in the literature.

We saw a large number of teacher studies in professional communities and in other institutional settings and we see this, in part, growing out of our first claim, and the emphasis we saw on small-scale qualitative work in the context where it takes place.

What then has been studied less? We list here some important examples that we think are notably missing. Clearly different lists could be made, as many things have not been studied, or studied less. We chose as a 
group to identify a small set of things of what is notably missing that has consequences for what we understand and can do in the practice teacher education and in policy surrounding it.

There have been few(er) studies on:

- Teacher learning outside of "reform" contexts. Many teachers are struggling to develop their teaching skills in environments where reform is not the dominant issue; but assisting a wide range of learners learn mathematics is. How does the dominant thrust of research on and in reform contexts help to understand this? Three critical issues flow from this:

- Teachers' learning from experience. We know much less than we should what teachers learn from experience, whether teachers learn from experience, and what supports learning from experience. Teachers spend most their time doing teaching. We understand far too little about what helps some teachers to develop from their own teaching while others do not.

- Teachers' learning to directly address inequality and diversity in their teaching of mathematics. We know far too little about teachers' learning to directly address inequality and diversity within their teaching of mathematics and here we include culture, gender, language, socio-economic status and mathematical background.

- Comparisons of different opportunities to learn. We lack comparisons in the field that compare different opportunities to learn. How does one approach to helping teachers to learn mathematics compare with another? We have studied these sorts of comparisons much less.

- "Scaling up." We know little about what happens when programs spread to multiple sites. We have also done less of studying what it means to scale up or what it means to extend a program that has worked in one setting to another setting - what works, what goes wrong, what do designers need to know and think about.

\section{REFLECTIONS ON OUR SURVEY TEAM WORK}

As with any research endeavor, it is important to reflect on one's own process of production. Before concluding with what each of the team members believes is important for the advancement of the field, we offer some reflections on our work, reflection both on what we have and have not done.

While accomplishing much of what we set out to do, we did not conduct a complete survey of literature around the world. Nor did we move on to systematically evaluate the quality of research in mathematics teacher education. In particular, we have not commented on: the use 
and development of theory; the use of appropriate methods; the quality of analysis and how well claims are supported by evidence.

We have also not been able to examine Claim 3 in depth. It is not surprising that research in English speaking countries dominates the literature we surveyed, as these publications are produced in English. Within the team, we argued extensively about the validity of this claim, and its relation to what was and was not included in the survey, and what comes to count and for whom as "the field." There are many anecdotes we could share about what is valued in terms of published research across different countries - and this varies from country to country. Moreover, the dominance we observed across key international publications and conferences does not imply there is no research elsewhere. We all know the deep history, experience and research that has constituted mathematics education in Europe, for example; and the wealth of experience across other continents. The point remains, that in these key publications, questions and problems constituted in English-speaking countries, and particularly the US, are dominant. What does this mean for our field? Does it have impact on the discourse and practice of the field, and if so how?

These are important tasks that remain to be accomplished. So we conclude now with brief comments from each of the team as to what we see as directions for the field. We look forward to a follow up review, perhaps at ICME11, and further debate in this journal and more widely on the claims and comments we have made.

\section{SO: WHAT NOW? COMMENTS AND DIRECTIONS FOR THE FIELD}

Jarmila: I am speaking from the position of someone outside of main teacher education theories, but who has access and/or is trying to have access to them. The field needs to find ways to transcend cultural and language boundaries to profit more from multiple traditions and schools of thought. A good practice in this direction is international summer schools where colleagues from various places can meet and discuss and work together. Recent developments in Europe demonstrate important shifts towards such cooperation. At the European Society for Research in Mathematics Education (ERME) conferences, and the Young European Researchers in Mathematics Education (YERME) summer schools, ${ }^{14}$ there are joint papers of authors from different parts of the world. Descriptions of different approaches with explicit attention to the links between them are more frequent. This is the result of significant effort of participating academics who are aware of the limitations of narrow perspectives. Through these practices, language and cultural barriers are also becoming a weaker obstacle for cooperation. 
Fou-Lai: The field needs better "local" (geographic, topic-specific, etc.) theories of teacher learning before trying to accomplish general theories about how teachers learn. Indeed, replication studies might go a long way to challenging and strengthening emergent theories, and so building robust general theories.

Konrad: More creative forms for presenting research results are needed, in order to represent the complexity of the field. The field has such variety and this could also be reflected in the presentation of our research. For example, we need authentic and interesting stories, both practicegrounded and theory-driven, and combinations of "reflective papers" by teachers with cross-analyses by teacher educators. In order to overcome the gap between theory and practice - to support teachers to come nearer to our field - more action research is needed, combining first-order and second-order action research: Teachers investigate their practice, and teacher educators investigate their support processes.

Jill: An enduring problem in mathematics teacher education is its task to build both mathematics and teaching identities. While we have learned a great deal about some of the specialty of teachers' knowledge, we need to understand better what it means to teach both mathematics and teaching in the same program. We do not understand well enough how mathematics and teaching, as inter-related objects, come to produce and constitute each other in teacher education practice. We lack adequate knowledge about what and how this happens inside a teacher education program, and then across ranging or contrasting programs, contexts and conditions. The field needs to understand better how mathematics and teaching combine in teachers' development and identities. As commented on earlier, in relation to Claim 2, this work requires us to develop stronger theoretical language(s) that produce a distance between mathematics teacher educators as researchers and the objects of their research.

Deborah: Teacher education research has been dominated by - and has profited from - small-scale studies, and from teacher educators studying their own contexts. For the field to grow to contribute to policy and practice, and to teachers' learning, however, we need to build capacity for smart, probing, comparative and large scale studies.

\section{ACKNOWLEDGMENTS}

The survey team members would like to thank the ICME10 Program Committee for the opportunity provided in doing this survey. In addition, we all thank our various agencies for support to attend the Congress in Copenhagen. In particular, we acknowledge the contribution by Jarmila 
Novotna that was supported by the Research project MSM 114100004

Cultivation of mathematical thinking and education in European culture. ${ }^{15}$

\section{NOTES}

1. We use "our" and "we" in relation to the mathematics education research community and teacher education community as each of us, though in different ways, is involved in mathematics teacher education, and mathematics education research.

2. Kilpatrick et al. (2001) have provided an interesting and useful elaboration of the notion of mathematical proficiency as interweaving conceptual understanding, procedural fluency, problem-solving, reasoning and disposition. This notion of proficiency as interwoven strands avoids tendencies of polarising various aspects of what it means to do mathematics, and to work mathematically.

3. The scale of provision of mathematics teachers across countries varies, with enormous shortages of quality teachers in some countries (e.g. US) to over-supply in others (e.g. Taiwan). Across countries, however, is the demand for quality teaching at all levels and so a scale of quality provision like never before.

4. Photos of diverse school classrooms and teacher education classrooms appear in the presentation cited in note 1 .

5. This point was made rather forcefully by the Danish Minister of Education in her opening address at ICME10.

6. See www.icme-10.dk

7. See for example Bishop et al. (2003).

8. See Sfard (2005).

9. Our survey selection is similar to that of Lerman, Xu and Tsatsaroni in their study of the field of mathematics education research as a whole i.e. key journals and PME proceedings. See, for example, Lerman et al. (2003).

10. Additional aspects of the study will be reported in forthcoming papers that expand on each of the claims presented below.

11. See for example, Chen and Lin (2004).

12. As there were only seven JRME papers between 1999 and 2003 that fitted our survey, this percentage can only be regarded as a very rough measure.

13. International Journal of Science and Mathematics Education, Kluwer, Volume 1, 2003; Volume 2, 2004.

14. Details of ERME and YERME can be found on the website, http://www.erme.uniosnabrueck.de/.

15. The references include specifically referred texts. The journals and proceedings surveyed are not repeated here.

\section{REFERENCES}

Bishop, A., Clements, M.A., Keitel, C., Kilpatrick, J. and Leung, F.: 2003 (eds.), Second International Handbook of Mathematics Education, Kluwer, Dordrecht.

Chen, I.R. and Lin, F.L.: 2004, 'A beginning mathematics teacher becoming professional through action research', Chinese Journal of Science Education 12(1), 83-105. 
Jaworski, B., Wood, T. and Dawson, S.: 1999 (eds.), Mathematics Teacher Education: Critical International Perspectives. Studies in Mathematics Education Series, Falmer Press, London.

Kilpatrick, J., Swafford, J. and Findell, B.: 2001, Adding It Up: Helping Children Learn Mathematics, National Academy Press, Washington DC, pp. 115-135.

Krainer, K. and Goffree, F.: 1999, Investigations into teacher education, 'Trends, future research, and collaboration', in Krainer, K., Goffree, F. and Berger, P. (eds.), On Research in Mathematics Teacher Education. European Research in Mathematics Education I.III. Forschungsinstitut fuer Mathematikdidaktik, Osnabrück, pp. 223-242

Krainer, K., Goffree, F. and Berger, P.: 1999 (eds.), On Research in Mathematics Teacher Education. European Research in Mathematics Education I.III. Forschungsinstitut fuer Mathematikdidaktik, Osnabrück.

Lerman, S.: 2001, 'A review of research perspectives on mathematics teacher education', in Lin, F.L. and Cooney, T.J. (eds.), Making Sense of Mathematics Teacher Education, Kluwer, Dordrecht, pp. 33-52.

Lerman, S., Xu, R. and Tsatsaroni, A.: 2003, The Production of Theories of Teaching and Learning: The Case of Mathematics. Unpublished paper presented at AERA Conference, 21-25 April, Chicago, U.S.A.

Lin, F.-L. and Cooney, T.: 2001 (eds.), Making Sense of Mathematics Teacher Education, Kluwer, Dordrecht-Boston-London.

Llinares, S. and Krainer, K.: in press, Mathematics (student) teachers and teacher educators as learners. To be published in A. Gutierrez and P. Boero (eds.), PME Research Handbook (working title)

Marneweck, L.: 2005, The Challenge of Curriculum Change Facing Primary School Teachers in Limpopo Province, Unpublished Ph.D. thesis, University of the Witwatersrand, Johannesburg.

Novotná, J.: 2002 (ed.), European Research in Mathematics Education II. Proceedings of the Second Conference of the European Society for Research in Mathematics Education, Charles University, Prague.

Peter-Koop, A., Begg, A. Breen, C. and Santos-Wagner, V.: 2003 (eds.), Collaboration in Teacher Education. Examples from the Context of Mathematics Education, Kluwer, Dordrecht-Boston-London.

Sfard, A.: 2005, What could be more practical than good research? Educational Studies in Mathematics 58(3), 390-411.

Skott, J.: 2001 'The emerging practices of a novice teacher: The roles of his school mathematics images', Journal of Mathematics Teacher Education 4(1), 3-28.

Strässer, R., Brandell, G., Grevholm, B. and Helenius, O.: 2004 (eds.), 'Educating for the Future', Proceedings of an International Research Symposium on Mathematics Teachers Education, NCM, Göteborg University, Sweden.

\section{JILL ADLER}

Chair of Mathematics Education

School of Education

University of the Witwatersrand

P/Bag 3, PO Wits, 2050

Johannesburg, South Africa

Telephone: +27 11 7173413; Fax: +27 117173259

E-mail: adlerj@educ.wits.ac.za 
DEBORAH BALL

University of Michigan

Ann Arbor, United States

KONRAD KRAINER

University of Klagenfurt

Klagenfurt, Austria

FOU-LAI LIN

National Taiwan Normal University

Taipei, Taiwan

JARMILA NOVOTNA

Charles University

Prague, The Czech Republic 